\title{
Education and occupational social class: which is the more important indicator of mortality risk?
}

George Davey Smith, Carole Hart, David Hole, Pauline MacKinnon, Charles Gillis, Graham Watt, David Blane, Victor Hawthorne
Department of Social Medicine, University of Bristol, Canynge Hall, Whiteladies Road, Bristol BS8 2PR G Davey Smith

Department of Public Health, University of Glasgow, Glasgow C Hart

P MacKinnon

West of Scotland Cancer Surveillance Unit, Ruchill Hospital, Glasgow

D Hole

C Gillis

Department of General Practice, University of Glasgow, Woodside Health Centre, Glasgow G Watt

Academic Department of Psychiatry, Charing Cross and Westminster Medical School, London

D Blane

University of Michigan, School of Public Health, Department of Epidemiology, Ann Arbor, Michigan, USA V Hawthorne

Correspondence to: Professor Davey Smith.

Accepted for publication 3 June 1997
Abstract

Study objectives-In the UK, studies of socioeconomic differentials in mortality have generally relied upon occupational social class as the index of socioeconomic position, while in the US, measures based upon education have been widely used. These two measures have different characteristics; for example, social class can change throughout adult life, while education is unlikely to alter after early adulthood. Therefore different interpretations can be given to the mortality differentials that are seen. The objective of this analysis is to demonstrate the profile of mortality differentials, and the factors underlying these differentials, which are associated with the two socioeconomic measures.

Design-Prospective observational study. Setting-27 work places in the west of Scotland.

Participants-5749 men aged 35-64 who completed questionnaires and were examined between 1970 and 1973.

Findings-At baseline, similar gradients between socioeconomic position and blood pressure, height, lung function, and smoking behaviour were seen, regardless of whether the education or social class measure was used. Manual social class and early termination of full time education were associated with higher blood pressure, shorter height, poorer lung function, and a higher prevalence of smoking. Within education strata, the graded association between smoking and social class remains strong, whereas within social class groups the relation between education and smoking is attenuated. Over 21 years of follow up, 1639 of the men died. Mortality from all causes and from three broad cause of death groups (cardiovascular disease, malignant disease, and other causes) showed similar associations with social class and education. For all cause of death groups, men in manual social classes and men who terminated full time education at an early age had higher death rates. Cardiovascular disease was the cause of death group most strongly associated with education, while the non-cardiovascular non-cancer category was the cause of death group most strongly associated with adulthood social class. The graded association between social class and all cause mortality remains strong and significant within education strata, whereas within social class strata the relation between education and mortality is less clear.

Conclusions-As a single indicator of socioeconomic position occupational social class in adulthood is a better discriminator of socioeconomic differentials in mortality and smoking behaviour than is education. This argues against interpretations that see cultural-rather than material-resources as being the key determinants of socioeconomic differentials in health. The stronger association of education with death from cardiovascular causes than with other causes of death may reflect the function of education as an index of socioeconomic circumstances in early life, which appear to have a particular influence on the risk of cardiovascular disease.

\section{( $F$ Epidemiol Community Health 1998;52:153-160)}

One of the most reproducible demographic findings, over time and within different countries, is the inverse association between socioeconomic position and mortality. ${ }^{1-5}$ Several different indicators of socioeconomic position have been used in such studies, ${ }^{6-11}$ including occupational social class, amount and type of education, employment grade, income, access to or ownership of various assets, and indices based on residential area characteristics. The choice of socioeconomic indicator often reflects which data are available, rather than any explicit theorisation of the possible effects of different dimensions of socioeconomic disadvantage. In the US measures based upon education have been widely used, because such information is the main socioeconomic indicator contained in various national data sets. ${ }^{12}$ In Britain occupational social class is the more usual measure and social class has been analysed with respect to mortality around each census since $1911 .^{13-15}$

The various indicators of socioeconomic position are generally related in a similar manner to mortality, but only on a few occasions have different indicators within the same database been analysed with respect to mortality. ${ }^{7-9}{ }^{11}{ }^{16-18}$ Different socioeconomic indicators show strong mutual associations ${ }^{19-22}$ and sometimes appear to be treated as though they are interchangeable proxy measures of an underlying entity, "socioeconomic status". The associations between health and the different socioeconomic indicators may have different implications and causes, however. For example the health effects of occupational hazards in 
unskilled manual jobs depend directly on work conditions, and reducing socioeconomic differentials consequent on such exposures requires changes to work environments. Conversely, health differences according to level of education have been attributed to the direct effects of education, including the acquisition of knowledge regarding health damaging behaviours, the ability to optimise use of health services, the development of time preferences favourable to health maintenance, an increasing willingness to invest in human capital, and the promotion of the psychological attributes of high self esteem and self efficacy. ${ }^{2123}{ }^{24}$ If the influence of both occupational social class and education act through associated differentials in income and living conditions, similar interdependent associations with mortality risk would be expected.

This study asks how different dimensions of socioeconomic position relate to health by analysing the association of education and occupational social class with health related behaviours, physiological risk factors, health status, and mortality risk within a large cohort of working men followed up for 21 years after a screening examination and questionnaire survey carried out in the early 1970s. To our knowledge only one analysis relating mortality risk simultaneously to both occupational social class and education has not been performed with UK data before this study. ${ }^{8}$

\section{Methods}

This analysis is based upon a cohort of men recruited from 27 workplaces in Glasgow, Grangemouth, and Clydebank (all in the west of Scotland) between 1970 and 1973. The workplaces included engineering, manufacturing, and petrochemical plants; a publishing house; civil service departments; administrative and professional divisions from British Rail; architectural institutes; legal and dental offices; and banking. Response rates were available for the workplaces from which $87 \%$ of the sample was recruited. For these sites $70 \%$ of those invited completed the questionnaire and attended for examination. The achieved sample was 6022 men and 1006 women, from which 5766 men aged $35-64$ at the time of examination have been included in this report. The mortality experience of the women could not be analysed as only 176 deaths have occurred to date.

The examinations used similar procedures to those used, and previously described with respect to, the MIDSPAN studies. ${ }^{25-28}$ An extensive questionnaire, completed by the subject, was checked at the screening examination. These examinations were conducted at clinics established for this purpose at, or near, the workplaces.

The information collected at baseline examination included sociodemographic data: age, age at which the participant finished full time education, occupational social class, whether a regular car driver; health status measures: angina, previous heart attack and intermittent claudication, from the Rose questionnaire, ${ }^{29}$ respiratory symptoms from the MRC questionnaire $^{30}$; health related behaviours: detailed smoking history, physical examination: height, weight, blood pressure (seated, taken with a London School of Hygiene and Tropical Medicine sphygmomanometer and with diastolic pressure being recorded at the disappearance of the fifth Korotkoff sound), lung function (with the Garthur Vitalograph), serum cholesterol and 6 lead electrocardiogram (leads I,II,III,aVR,aVL, and aVF).

Social class was coded according to the Registrar General's classification ${ }^{31}$ and treated at six levels for analysis by social class alone and at four levels-I and II; III non-manual; III manual; IV and V-for analyses in which both social class and education were included. Age at leaving full time education was categorised as $12-14 ; 15-16 ; 17-18$, and $19+$.

Persistent phlegm was defined as usually bringing up phlegm from the chest first thing in the morning on most days for as much as three months in winter each year. "Infective phlegm" was defined as usually bringing up phlegm from the chest first thing in the morning in winter and having had a period of increased cough and phlegm lasting for three weeks or more in the past three years. Breathlessness was defined by responding positively to the question: "Do you get short of breath walking with people of your own age on level ground?". Bronchitis was defined as having persistent and "infective" phlegm and being breathless. ${ }^{30}$

Angina was considered present if chest pain or discomfort when walking uphill or hurrying was: to be sited in the sternum or the left chest and arm; caused the subject to stop or slow down; went away when the subject stopped or slowed down; and went away in 10 minutes or less. $^{29}$

For forced expiratory volume in one second $\left(\mathrm{FEV}_{1}\right)$, the best of two expirations was recorded. To estimate impairment, the expected $\mathrm{FEV}_{1}$ was obtained from linear regression equations of age and height:

Expected $\mathrm{FEV}_{1}=-278.06+4.33 \times$ height $-3.06 \times$ age. Age is in years, height in $\mathrm{cm}$, and the value is divided by 100 to give $\mathrm{FEV}_{1}$ in litres. The coefficients were derived from a healthy subset of the population who never smoked and answered no to questions on phlegm, breathlessness, wheezy or whistling chest and if weather affected breathing. The adjusted FEV1 was calculated by:

Adjusted $\mathrm{FEV}_{1}(\%)=$ (Actual $\mathrm{FEV}_{1} / \mathrm{Ex}-$ pected $\left.\mathrm{FEV}_{1}\right) \times 100$

The ECG was coded according to the Minnesota system, ${ }^{29}$ with any of the following codes, which encompass diagnoses of definite myocardial infarction, myocardial ischaemia, and left bundle branch block, being considered evidence of ischaemia: $1.1-1.3,4.1-4.4,5.1-$ 5.3, 7.1.

Data on social class and education were missing on nine and eight men respectively. These men were excluded from the present analyses, which are therefore based on 5749 participants.

Mortality over a 21 year follow up period has been ascertained from flagging at the National Health Service Central Registry in Edinburgh, 
Table 1 Population characteristics according to social class. (Age adjusted means and proportions)

\begin{tabular}{|c|c|c|c|c|c|c|c|c|}
\hline & \multicolumn{6}{|c|}{ Social class } & \multirow[t]{2}{*}{ Total } & \multirow[t]{2}{*}{ Trend } \\
\hline & $I$ & II & $I I I N$ & IIIM & $I V$ & $V$ & & \\
\hline Number & 762 & 1102 & 1036 & 1648 & 993 & 208 & 5749 & \\
\hline Age at screening ${ }^{\star}$ & 47.7 & 47.9 & 47.7 & 48.1 & 49.0 & 51.5 & 48.2 & $\mathrm{p}=0.0001$ \\
\hline Systolic blood pressure $(\mathrm{mm} \mathrm{Hg})$ & 131.1 & 131.2 & 133.1 & 136.4 & 136.3 & 133.0 & 134.0 & $\mathrm{p}=0.0001$ \\
\hline Diastolic blood pressure ( $\mathrm{mm} \mathrm{Hg}$ ) & 82.3 & 83.2 & 83.4 & 84.9 & 84.5 & 84.2 & 83.9 & $\mathrm{p}=0.0001$ \\
\hline Cholesterol $(\mathrm{mmol} / \mathrm{l})$ & 6.4 & 6.1 & 6.0 & 5.7 & 5.6 & 5.6 & 5.9 & $\mathrm{p}=0.0001$ \\
\hline Height $(\mathrm{cm})$ & 176.3 & 175.0 & 173.2 & 171.2 & 170.6 & 170.4 & 172.8 & $\mathrm{p}=0.0001$ \\
\hline Body mass index $\left(\mathrm{kg} / \mathrm{m}^{2}\right)$ & 24.9 & 25.3 & 25.1 & 25.3 & 25.1 & 25.3 & 25.2 & $\mathrm{p}=0.15$ \\
\hline FEV1 score (\%) & 99.3 & 99.1 & 95.7 & 90.8 & 90.6 & 87.7 & 94.3 & $\mathrm{p}=0.0001$ \\
\hline Angina $(\%)$ & 4.4 & 5.0 & 6.7 & 7.3 & 6.7 & 8.1 & 6.2 & $\mathrm{p}=0.001$ \\
\hline ECG ischaemia (\%) & 5.2 & 5.5 & 6.8 & 5.6 & 6.4 & 4.0 & 5.8 & $\mathrm{p}=0.61$ \\
\hline MRC bronchitis (\%) & 0.1 & 0.9 & 1.9 & 3.2 & 3.3 & 4.8 & 2.2 & $\mathrm{p}=0.0001$ \\
\hline Never smoked (\%) & 21.4 & 21.2 & 19.2 & 14.3 & 14.0 & 16.4 & 17.6 & $\mathrm{p}=0.0001$ \\
\hline Current cigarette smokers (\%) & 42.3 & 45.2 & 54.9 & 61.7 & 65.4 & 67.4 & 55.5 & $\mathrm{p}=0.0001$ \\
\hline Ex-smokers (\%) & 31.4 & 29.5 & 23.8 & 21.9 & 19.0 & 15.9 & 24.2 & $\mathrm{p}=0.0001$ \\
\hline Average number of cigarettes smoked per dayt & 20.2 & 19.4 & 18.3 & 19.2 & 18.6 & 17.4 & 19.0 & $\mathrm{p}=0.004$ \\
\hline Regular drivers (\%) & 75.4 & 72.1 & 42.6 & 47.8 & 34.7 & 18.4 & 51.8 & $\mathrm{p}=0.0001$ \\
\hline School leavers aged 16 or under $(\%)$ & 24.2 & 65.6 & 84.8 & 98.3 & 98.7 & 99.1 & 79.8 & $\mathrm{p}=0.0001$ \\
\hline
\end{tabular}

^Not age adjusted. †For current cigarette smokers only.

Table 2 Population characteristics according to age at leaving full time education. (Age adjusted means and proportions)

\begin{tabular}{|c|c|c|c|c|c|}
\hline & \multicolumn{4}{|c|}{ Age leaving full time education } & \multirow[t]{2}{*}{ Trend } \\
\hline & $19+$ & $17-18$ & $15-16$ & $12-14$ & \\
\hline Number & 504 & 659 & 1652 & 2934 & \\
\hline Age at screening $\star$ & 47.1 & 47.7 & 46.3 & 49.7 & $\mathrm{p}=0.0001$ \\
\hline Systolic blood pressure $(\mathrm{mm} \mathrm{Hg})$ & 131.4 & 131.3 & 134.1 & 134.9 & $\mathrm{p}=0.0001$ \\
\hline Diastolic blood pressure $(\mathrm{mm} \mathrm{Hg})$ & 82.8 & 82.7 & 83.8 & 84.4 & $\mathrm{p}=0.0001$ \\
\hline Cholesterol $(\mathrm{mmol} / \mathrm{l})$ & 6.4 & 6.2 & 5.9 & 5.7 & $\mathrm{p}=0.0001$ \\
\hline Height $(\mathrm{cm})$ & 176.7 & 175.4 & 173.4 & 171.3 & $\mathrm{p}=0.0001$ \\
\hline Body mass index $\left(\mathrm{kg} / \mathrm{m}^{2}\right)$ & 25.0 & 25.1 & 25.0 & 25.3 & $\mathrm{p}=0.013$ \\
\hline FEV1 score (\%) & 101.2 & 99.4 & 95.1 & 91.5 & $\mathrm{p}=0.0001$ \\
\hline Angina $(\%)$ & 3.5 & 5.9 & 5.2 & 6.8 & $\mathrm{p}=0.002$ \\
\hline ECG ischaemia (\%) & 4.7 & 5.8 & 6.4 & 5.6 & $\mathrm{p}=0.75$ \\
\hline MRC bronchitis (\%) & 0.5 & 0.3 & 1.4 & 3.2 & $\mathrm{p}=0.0001$ \\
\hline Never smoked (\%) & 20.5 & 21.0 & 19.4 & 15.5 & $\mathrm{p}=0.0001$ \\
\hline Current cigarette smokers (\%) & 41.7 & 47.6 & 53.2 & 60.4 & $\mathrm{p}=0.0001$ \\
\hline Ex-smokers $(\%)$ & 33.1 & 27.5 & 24.8 & 22.2 & $\mathrm{p}=0.0001$ \\
\hline Average number of cigarettes smoked per dayt & 20.1 & 19.2 & 18.8 & 18.9 & $\mathrm{p}=0.12$ \\
\hline Regular drivers (\%) & 81.7 & 63.8 & 53.5 & 42.5 & $\mathrm{p}=0.0001$ \\
\hline Social class I or II (\%) & 95.6 & 72.2 & 37.1 & 11.8 & $\mathrm{p}=0.0001$ \\
\hline
\end{tabular}

^Not age adjusted. $†$ For current cigarette smokers only.

which also provides death certificates coded according to the ninth revision of the International Classification of Diseases (ICD).

Death rates have been calculated using a person years at risk based lifetable approach. These rates have been standardised for age by the direct method, using the total study population as the standard. Tests for trend for age adjusted rates have been obtained through proportional hazards regression, using PROC PHREG in the SAS system, with age and the socioeconomic indicator coded as a continuous variable as covariates. Continuous variables have been age standardised using PROC GLM, with tests for trend for age adjusted means being obtained through PROC REG. Categorical variables have been age standardised by the direct method and tests for trend performed in PROC LOGIST.

Table 3 Age adjusted prevalence (per 100) of current cigarette smoking. (Number in each category in parentheses)

\begin{tabular}{llllll}
\hline \multicolumn{2}{c}{ Social Class } & \multicolumn{2}{c}{ Test for trend } \\
\cline { 2 - 4 } & I and II & IIIN & IIIM & IV and $V$ & \\
\hline Age leaving full time education & & & & \\
$19+$ & $39.5(484)$ & $60.0(15)$ & $100.0(1)$ & $100.0(4)$ & $\mathrm{p}=0.010$ \\
$17-18$ & $45.2(478)$ & $53.2(141)$ & $53.7(28)$ & $50.0(12)$ & $\mathrm{p}=0.13$ \\
$15-16$ & $45.4(553)$ & $54.4(460)$ & $58.2(436)$ & $64.5(203)$ & $\mathrm{p}=0.0001$ \\
$12-14$ & $45.8(349)$ & $55.7(420)$ & $63.0(1183)$ & $65.8(982)$ & $\mathrm{p}=0.0001$ \\
Test for trend & $\mathrm{p}=0.066$ & $\mathrm{p}=0.69$ & $\mathrm{p}=0.021$ & $\mathrm{p}=0.63$ & \\
\hline
\end{tabular}

Proportional hazards coefficients and their standard errors were calculated using Cox's model. ${ }^{32}$ Adjustment for age and other risk factors was performed by including terms for these in the proportional hazards models. Exponentiated hazards coefficients are taken as indicators of relative rates of mortality. Stratification of the proportional hazards regression analysis was also performed, with social class or age at leaving full time education as the stratification variable. This allows the baseline hazard to vary between strata, producing summary measures of the relative rates of mortality seen within the strata.

\section{RELATIVE INDEX OF INEQUALITY}

To compare the magnitude of trends of current smoking and all cause mortality with social class and with age at leaving full time education, the relative index of inequality $(\mathrm{RII})^{514}$ has been calculated. Comparisons of ratio measures between social class or education groups suffer from the fact that the groups are of different size. It may be expected that the classification producing smaller groups at the margins would lead to larger ratios of, say, mortality, between the top and bottom categories, because finer discrimination of extremes of socioeconomic position is achieved. The RII is explicitly constructed to avoid this problem. 
Table 4 Age adjusted 21 year death rates according to social class (per 10000 person years)

\begin{tabular}{|c|c|c|c|c|c|c|c|}
\hline & \multicolumn{6}{|c|}{ Social class } & \multirow[t]{2}{*}{ Trend } \\
\hline & $I$ & $I I$ & IIIN & IIIM & $I V$ & $V$ & \\
\hline \multicolumn{8}{|l|}{ All cause } \\
\hline No of deaths & 156 & 242 & 293 & 530 & 334 & 84 & \\
\hline Death rate & 101.1 & 110.0 & 139.5 & 153.0 & 152.6 & 170.5 & $\mathrm{p}=0.0001$ \\
\hline \multicolumn{8}{|l|}{ All CVD } \\
\hline No of deaths & 65 & 138 & 155 & 273 & 172 & 38 & \\
\hline Death rate & 48.0 & 66.8 & 79.8 & 86.4 & 87.7 & 78.7 & $\mathrm{p}=0.0001$ \\
\hline \multicolumn{8}{|l|}{ All cancer } \\
\hline No of deaths & 64 & 68 & 91 & 166 & 109 & 25 & \\
\hline Death rate & 41.7 & 35.4 & 52.7 & 57.4 & 57.8 & 60.1 & $\mathrm{p}=0.005$ \\
\hline \multicolumn{8}{|c|}{ Non-CVD, non-cancer } \\
\hline No of deaths & 27 & 36 & 47 & 91 & 53 & 21 & \\
\hline Death rate & 21.0 & 20.2 & 26.8 & 32.4 & 30.7 & 59.1 & $\mathrm{p}=0.0001$ \\
\hline
\end{tabular}

It requires classifications to be defined hierarchically - that is, social class being I and II, then IIIN, then IIIM, then IV and V; or age at leaving full time education being $12-14$, then 15-16, then 17-18, then 19+. Socioeconomic position of each group is assigned a value between 0 and 1 , according to the proportion of participants with a higher position than the midpoint of each group within this hierarchy. This assignment is done separately within each five year band for age at study entry, to allow production of an age adjusted measure of inequality. If in a particular five year age band $10 \%$ of men (that is, 0.1 as a proportion of the whole study population in this age band) is in the social class I and II category, this group is assigned a value of 0.05 , which is the proportion of the population above its midpoint. If the next group, social class IIIN, contains an additional $12 \%$ of the men in this age band then the proportion of the population above the midpoint of this group is $0.1+0.12 / 2$ $=0.16$. These indicators were created in a similar fashion for social class and age at leaving full time education, in both cases using four levels.

These numerical indicators of socioeconomic position (SEP) are then related to mortality through Poisson regression ${ }^{5}$ :

$\log (\mathrm{Dij})=\log (\mathrm{Pij})+\alpha_{\mathrm{i}}+\beta^{\star} \mathrm{SEPj}$

with $\mathrm{D}$ being the number of deaths and $\mathrm{P}$ the number of person years at risk in the ${ }_{\mathrm{i}}$ th 5 year age group and th socioeconomic group. Exponentiating $\beta$ yields the RII, which is the relative risk of mortality comparing a socioeconomic position indicator of 1 to 0 - that is, the bottom to the top of the socioeconomic hierarchy. A similar logistic regression method, with $D$ representing the number of smokers and $\mathrm{P}$ the

Table 5 Age adjusted 21 year death rates according to age at leaving full time education (per 10000 person years)

\begin{tabular}{llllll}
\hline & \multicolumn{2}{l}{ Age leaving full time education } & \multirow{2}{*}{ Trend } \\
\cline { 2 - 4 } & $19+$ & $17-18$ & $15-16$ & $12-14$ & \\
\hline $\begin{array}{lllll}\text { All cause } \\
\quad \text { No of deaths }\end{array}$ & 96 & 150 & 397 & 996 & \\
$\quad \begin{array}{l}\text { Death rate } \\
\text { All CVD }\end{array}$ & 100.8 & 112.8 & 129.3 & 148.5 & $\mathrm{p}=0.0001$ \\
$\quad$ No of deaths & 40 & 81 & 212 & 508 & \\
$\quad \begin{array}{l}\text { Death rate } \\
\text { All cancer }\end{array}$ & 47.5 & 66.7 & 75.0 & 83.9 & $\mathrm{p}=0.0001$ \\
$\quad \begin{array}{l}\text { No of deaths } \\
\text { Death rate }\end{array}$ & 36 & 47 & 125 & 315 & \\
$\begin{array}{l}\text { Non-CVD, non-cancer } \\
\quad \text { No of deaths }\end{array}$ & 38.9 & 39.6 & 47.4 & 54.4 & $\mathrm{p}=0.004$ \\
$\quad$ Death rate & 20 & 22 & 60 & 173 & \\
\hline
\end{tabular}

number of study participants was used to produce the RII for smoking, which in this case is the odds ratio for being a smoker at the bottom compared with the top of the socioeconomic hierarchy. The larger the RII, the greater the degree of inequality across a socioeconomic hierarchy.

\section{Results}

CHARACTERISTICS OF STUDY PARTICIPANTS

Table 1 gives the characteristics of the study population according to social class. On average men in manual jobs were older, shorter, had higher blood pressure, lower serum cholesterol, poorer lung function, higher prevalences of angina and bronchitis, and were more likely to be current smokers but, if smokers, used less cigarettes per day. A strong association between social class and education was observed, and men in the manual classes were considerably less likely to be regular car drivers. Being a regular car driver is taken to be in part a marker for ownership of a car, which has been used in various studies as an indicator of available income. ${ }^{811}$ In table 2 the data are presented according to age at leaving full time education. The gradients by education are similar to those seen with respect to social class.

SMOKING IN RELATION TO SOCIAL CLASS AND EDUCATION

Table 3 gives the age adjusted prevalences of current smoking by social class and education. While there are few men in the manual social classes who had left school above the age of 16 , the pattern of higher prevalence of smoking among the men in manual jobs within education strata seems clearer than the corresponding association between education and smoking within social class strata. The RIIs for current smoking are 2.66 (95\% confidence intervals $2.17,3.26$ ) for education and 3.55 $(2.93,4.30)$ for social class categorised at four levels. A test between these RIIs shows that they differ at a conventional level of significance $(\mathrm{p}=0.044)$. A logistic regression analysis, in which current smoking (yes/no) is the outcome, and linear terms for education and social class fitted together with age as independent variables, yielded odds ratios of 0.90 $(0.84,0.96)$ for one education category and $0.77(0.73,0.82)$ for one social class category, both at four levels. The logistic regression 
Table 6 Stratified and unstratified age adjusted relative rates of mortality (and 95\% confidence intervals) according to social class and age at leaving full time education

\begin{tabular}{lllll}
\hline & Social class & $\begin{array}{l}\text { Social class } \\
\text { (stratified by } \\
\text { education) }\end{array}$ & $\begin{array}{l}\text { Age leaving full time } \\
\text { education }\end{array}$ & $\begin{array}{l}\text { Age leaving full time education } \\
\text { (stratified by social class) }\end{array}$ \\
\hline All cause & 1.17 & 1.12 & 1.19 & 1.07 \\
All CVD & $(1.12,1.22)$ & $(1.07,1.18)$ & $(1.12,1.25)$ & $(0.99,1.14)$ \\
All cancer & 1.16 & 1.11 & 1.20 & 1.09 \\
& $(1.09,1.23)$ & $(1.03,1.09)$ & $(1.11,1.30)$ & $(0.99,1.21)$ \\
Non-CVD, non-cancer & 1.16 & 1.13 & 1.15 & 1.04 \\
& $(1.08,1.25)$ & $(1.03,1.24)$ & $(1.05,1.27)$ & $(0.92,1.17)$ \\
& 1.22 & 1.18 & 1.20 & 1.03 \\
\end{tabular}

analysis thus supports the RII analysis in indicating that social class is more strongly related to smoking behaviour than is education.

\section{MORTALITY ACCORDING TO SOCIAL CLASS AND EDUCATION}

Mortality from all causes and from broad cause of death groups show clear increases from the non-manual to the manual social classes (table 4). Similar gradients are seen according to education (table 5). The RIIs for all cause mortality are $1.84(1.54,2.19)$ for social class treated at four levels and $1.73(1.42,2.10)$ for education. These do not differ significantly from each other $(p=0.65)$.

Proportional hazards models were also fitted containing age and linear terms for the socioeconomic measures. For a one category change in social class (treated at four levels), the age adjusted relative rate of mortality is $1.17(1.12,1.22)$. In analyses stratified by the four education groups, the relative rate for a one category change in social class is 1.12 $(1.07,1.18)$. For a one category change in education, the age adjusted relative rate of mortality is similar to that seen for social class: 1.19 $(1.12,1.25)$. However in this case stratifying by the four social class categories leads to greater attenuation of the relative rate of mortality according to education category, to $1.07(0.99$, 1.14). Table 6 presents similar results for the major cause of death groups. Cardiovascular disease is the cause of death group most strongly associated with education, while the non-cardiovascular non-cancer category is the cause of death group most strongly associated with adulthood social class.

Table 7 Age adjusted 21 year death rates according to age at study entry and age at leaving full time education per 10000 person years

\begin{tabular}{llllll}
\hline & \multicolumn{2}{l}{ Age at leaving full time education } & \multirow{2}{*}{ Trend } \\
\cline { 2 - 5 } Age band & $19+$ & $17-18$ & $15-16$ & $12-14$ & \\
\hline $35-49$ & 38 & 54 & 169 & 323 & $\mathrm{p}=0.0001$ \\
& 60.2 & 67.3 & 86.4 & 97.9 & \\
$50-64$ & 58 & 154 & 228 & 673 & \\
& 151.8 & 169.9 & 183.4 & 212.0 & $\mathrm{p}=0.0001$ \\
\hline
\end{tabular}

Table 8 Stratified and unstratified age adjusted relative rates of mortality (and 95\% confidence intervals) according to social class and age at leaving full time education, according to age at study entry

\begin{tabular}{lllll}
\hline Age band & Social class & $\begin{array}{l}\text { Social class } \\
\text { (stratified by } \\
\text { education) }\end{array}$ & $\begin{array}{l}\text { Age leaving full } \\
\text { time education }\end{array}$ & $\begin{array}{l}\text { Age leaving full time education } \\
\text { (stratified by social class) }\end{array}$ \\
\hline $35-49$ & 1.23 & 1.20 & 1.21 & 1.04 \\
$50-64$ & $(1.15,1.32)$ & $(1.10,1.31)$ & $(1.10,1.32)$ & $(0.92,1.16)$ \\
& 1.14 & 1.09 & 1.17 & 1.07 \\
& $(1.08,1.20)$ & $(1.02,1.16)$ & $(1.09,1.25)$ & $(0.98,1.17)$ \\
\hline
\end{tabular}

MORTALITY FOR DIFFERENT AGE GROUPS

As average age at leaving full time education changed over the period during which the men in this study were at school, mortality by age of leaving full time education has been examined in two age bands (table 7). Age at study entry correlates closely with relative age at the time of schooling, as the baseline screening period was short. Clear mortality differentials are seen for both age bands. Relative mortality differentials by both social class and education are greater in the younger age band (table 8). Simultaneous analysis of education and social class within the age bands yields identical findings to those seen in the whole cohort. Differentials according to education are reduced to nonsignificance by stratification by social class, while differentials by social class are only moderately attenuated and remian significant on stratification by education (table 8).

\section{Discussion}

British studies of the association between the socioeconomic position and mortality of individuals have generally used occupationally based socioeconomic measures. Various versions of the Registrar General's social class classification have been used in the decennial supplements, ${ }^{13-15}$ the major source of data on this subject. The Longitudinal Study, involving the linkage of a $1 \%$ sample from the 1971 census to death certification data, complements these reports by demonstrating large and increasing mortality differentials over the two decades of post-census follow up. ${ }^{33}$ Educational achievement, indicated by highest qualifications received, is also inversely associated with all cause death rate in the Longitudinal Study. ${ }^{78}$

The mortality differentials according to social class in this study are very similar to those for men of the same age group seen around 1981, the midpoint of the follow up period, in Scotland. For men aged 55 to 64 social classes IV and V had death rates $66 \%$ higher than social classes I and II in the general Scottish population. ${ }^{34}$ In this study population social class IV and V men experienced an age adjusted death rate $59 \%$ higher than that of social class I and II men. The general population data also show mortality differentials for the major cause of death groups similar in magnitude to those seen in this study. Our workplace sample thus appears a reasonable model for studying factors underlying socioeconomic differentials in mortality risk in the general population. 
Age at leaving full time education will be determined by several factors, including economic status of the family, aptitude of the child, employment opportunities at the time of reaching minimum school leaving age, and legislation. It would be inappropriate to consider the effects of differences in age at leaving full time education produced simply by legislative change, as this would merely reflect year of birth. The men included in this study were born between 1907 and 1938 and would have reached age 14 between 1921 and 1952. A minimum school leaving age of 14 was introduced in 1904 in Scotland and was raised to 15 in 1947 . However, enforcement was variable and many children left school at younger ages. ${ }^{35}$ There were only 438 men in our study who according to legislation could not leave school at age 14 because of the 1947 legislative change. Excluding these men from the analyses did not materially change our findings (basic tables available from authors). Analyses were also repeated in two age groups, to allow for any broad secular changes in the meaning and implications of age at leaving full time education. Findings for the two age groups were very similar.

Most studies that analyse education and adult socioeconomic measures separately in relation to mortality risk within the same dataset demonstrate associations in the expected direction..$^{7-9}$ Analyses relating mortality risk to both occupational social class and education simultaneously have been performed only once with UK data before this study, to our knowledge. ${ }^{8}$ We found that social class in adulthood seems to be the more important determinant of mortality. In the US, the National Longitudinal Mortality Study ${ }^{18}$ has been analysed with respect to household income, years of education, and occupation. For working age men pronounced attenuation of the association between years of education and mortality occurs when other socioeconomic indices are taken into account. ${ }^{18}{ }^{37}$ In a US study, the National Longitudinal Survey of Older Men, years of education shows a strong inverse association with mortality risk. However after adjustment for lifetime income and wealth this association essentially disappears. ${ }^{38}$ In a collaborative study with centres in Kaunas (Lithuania) and Rotterdam (Holland) both occupational social class and education were related to mortality risk over a 10 year follow up period. Adjustment for occupational level greatly reduced the association of mortality with education, while adjustment for education left a relatively substantial occupational effect. ${ }^{39}$ Other studies have revealed contributions of both education and adult socioeconomic measures to mortality risk, although the analyses that have been presented do not allow for an adequate evaluation of the relative importance of these two factors. ${ }^{40} 41$

In this study cigarette smoking was more strongly related to current occupational social class than age at leaving full time education. This suggests that it is the social environment in adulthood that maintains, or initiates, smoking behaviour. Age at leaving full time educa-
KEY POINTS

- Occupational social class and education are both strongly associated with mortality in middle aged men.

- Social environment in adulthood is the key determinant of smoking behaviour in these middle aged men.

- Occupational social class is more strongly associated with overall and noncardiovascular mortality than is the educational measure.

- The educational measure is more strongly associated with cardiovascular than with other causes of death.

- Epidemiological studies and public health policy need to incorporate a lifecourse perspective on socioeconomic inequalities in health.

tion is in this formulation mainly related to smoking behaviour through its determination of occupational level in adulthood. Similar findings, of more consistent differentials in smoking by occupation than by educational level, have come from Kaunas and Rotterdam. $^{39}$ A US study came to opposite conclusions, although the occupational classification used in this study and the manner in which it was statistically treated make the results hard to interpret. ${ }^{21}$

The pathways linking education and mortality have been discussed at some length. ${ }^{23} 244243$ Three basic positions can be distinguished. Firstly, Fuchs and others have argued that people with different educational levels differ in unobservable ways, including having time preferences favourable to long term investment in their future. Rather than good health being caused by education, underlying unobserved factors might lead to both good health and better education. Secondly, education may act through improving health related knowledge, which allows the choice of healthier lifestyles, which in turn reduce mortality risk. Thirdly, education may act through allowing for favourable employment opportunities with higher income levels and more favourable living conditions throughout adult life. Of health related behaviours, smoking has probably been most investigated with respect to education. ${ }^{43} 44$ When health related knowledge is taken into account strong associations between education and smoking remain. ${ }^{43}$ This is consistent with the finding in this study that adulthood occupational social class is more strongly related to smoking behaviour than age at leaving full time education and suggests that effects beyond those of knowledge are involved. Both the theory that unobservable differences in time preference and direct effects of education on health knowledge are responsible for the association between education and mortality risk would predict stronger associations with respect to education than occupational social class. Our data suggest that both education and social class are serving as indices of life course socioeconomic experience. In this sense, 
education is important for the opportunities it creates for improved material conditions of life that follow the completion of formal education, rather than for particular specific effects of education itself. The direct associations between socioeconomic position-either indexed by social class or by education - and serum cholesterol concentrations are striking in this regard. Groups leaving school with more full time education and those in the professional and managerial social classes have higher cholesterol values than those leaving school at minimum school leaving age and those ending up in manual occupations. This suggests similar patterns with respect to dietary fat intake by socioeconomic position, however it is indexed, and no special effect of education on dietary practices in this regard. If education has its influence through ability to assimilate health related knowledge than an inverse gradient would have been expected, given that publicity relating animal fat intake to coronary heart disease risk was already circulating (albeit in limited form) in the early 1970s.

In this study age at leaving full time education was the only index of education available. We have no data regarding evening classes or day release schemes, which are important sources of post-school education. It may be that indices of educational achievement, rather than simply school leaving age, would show different associations with risk factors and mortality. There would, however, be a strong correlation between the two measures, with most people leaving at age 14 or under not obtaining the higher school qualifications that would have been received by those leaving at 17 or 18 and only those staying in full time education to beyond the age of 19 obtaining college or university qualifications. Studies with detailed data on both amount of education and educational achievement, together with subsequent life trajectory, would be required to examine the hypothesis that underlying differences generate health differentials between those who do and do not obtain higher qualifications.

The main conclusion of this study is that age at leaving full time education and occupational social class are both strongly related to risk factors and to mortality. There is no evidence that education plays a predominant part in this regard. Smoking behaviour seems more strongly related to the adulthood socioeconomic indicator, in keeping with the suggestion that it is social environment that maintains this behaviour. ${ }^{45}$ Some differences in mortality associations for particular cause of death groups are seen in these data. In multivariable analysis non-cardiovascular disease non-cancer mortality is considerably more strongly associated with occupational social class than with education. This could reflect direct occupational exposures that influence respiratory and digestive system disease, with such exposures being better indexed by social class than age at leaving full time education. Cardiovascular disease mortality is the cause of death group most strongly associated with education, which may reflect the particular importance of socioeco- nomic circumstances in childhood (and factors related to this) with respect to risk of coronary heart disease and stroke. ${ }^{46-48}$

Single indicators of social economic position do not maximally discriminate between social groups at differing levels of mortality risk, with the use of cumulative or multiple indicators producing greater differentiation in this regard. $^{81011} 47$ Future studies should collect measures of socioeconomic position across the life course and use combined measures if they intend to show the full extent of socioeconomic differentiation or adequately control for possible confounding of associations between putative risk factors and disease risk by exposures which are socioeconomically patterned.

Funding: the investigation of socioeconomic determinants of mortality in this cohort is supported by a grant from the NHS Research and Development Initiative.

1 Schellekens J. Mortality and socio-economic status in two eighteenth-century Dutch villages. Population Studies 1989;43:391-404.

2 Fox J. Health inequalities in European countries. Aldershot: Gower, 1989

3 Davey Smith G, Bartley M, Blane D. The Black Report on socioeconomic inequalities in health 10 years on. BMF 1990;301:373-7.

4 Davey Smith G, Carroll D, Rankin S. Socio-economic differentials in mortality: evidence from Glasgow graveyards. $B M \mathcal{F}$ 1992;305:1554-7.

5 Kunst AE, Mackenbach JP. The size of mortality differences associated with educational level in nine industrialized countries. Am F Public Health 1994;84:932-7.

6 Liberatos P, Link BG, Kelsey JL. The measurement of social class in epidemiology. Epidemiol Rev 1988;10:87-121.

7 Moser K, Pugh H, Goldblatt P. Mortality and the social classification of women. In: Goldblatt P, ed. Longitudinal study: mortality and social organisation. London: HMSO, 19tudy: mortality

8 Goldblatt P. Mortality and alternative social classifications. In: Goldblatt P, ed. Longitudinal study: mortality and social organisation. London: H M S O, 1990:163-92.

9 Rogot E, Sorlie PD, Johnson NJ, Schmitt C. A mortality study of 1.3 million persons by demographic, social, and economic factors: 1979-1985 Follow-Up, U.S. National Longitudinal Mortality Study. Washington D C: N I H, 1993.

10 Davey Smith G, Blane D, Bartley M. Explanations for socioeconomic differentials in mortality: evidence from Britain and elsewhere. European fournal of Public Health 1994;4:131-44.

11 Davey Smith G, Shipley MJ, Rose G. The magnitude and causes of socio-economic differentials in mortality: further evidence from the Whitehall study. $\mathcal{F}$ Epidemiol Community Health 1990;44:260-5.

12 Krieger N, Fee E. Social class: the missing link in U.S. health data. Int $\mathcal{f}$ Health Serv 1994;24:25-44.

13 Stevenson THC. The social distribution of mortality from different causes in England and Wales, 1910-12. Biometrika 1923;15:382-400.

14 Pamuk ER. Social class inequality in mortality from 1921 to 1972 in England and Wales. Population Studies 1985;39:1731.

15 Blane D, Davey Smith G, Bartley M. Social class differences in years of potential life lost: size, trends and principal causes. BMf 1990;301:429-32.

16 Hinkle LE, Whitney H, Lehman EW, et al. Occupation, education and coronary heart disease. Science 1968;161: 238-46.

17 Mare RD. Socio-economic careers and differential mortality among older men in the United States. In: Vallin J, D'Souza S, Palloni A, eds. Measurement and analysis of mortality: new approaches. Oxford: Clarendon Press, 1990:362-87.

18 Sorlie PD, Backlund E, Keller JB. U.S. Mortality by Sorlie PD, Backlund E, Keller JB. U.S. Mortality by
economic, demographic, and social characteristics: The National Longitudinal Mortality Study. Am f Public Health National Longitu

19 Reid I. Social class differences in Britain: life-chances and life-styles. Glasgow: Fontana Press, 1989.

20 OPCS. General Household Survey 1988. London: D H S S, 1990.

21 Winkleby MA, Jatulis DE, Frank E, Fortmann SP. Socioeconomic status and health: how education, income, and occupation contribute to risk factors for cardiovascular disease. Am F Public Health 1992;82:816-20.

22 Pekkanen J, Tuomilehto J, Uutela A, Vartiainen E, Nissinen A. Social class, health behaviour, and mortality among men and women in eastern Finland. BMF 1995;311:589-93.

23 Fuchs VR. Economics, health, and post-industrial society. Milbank Memorial Fund Quarterly 1979;57:153-82.

24 Pincus T, Callahan LF. Associations of low formal education level and poor health status: behavioural, in 
addition to demographic and medical, explanations? $\mathcal{f}$ Clin Epidemiol 1994;47:355-61.

25 Hawthorne VM, Gillis CR, Lorimer AR, Calvert FR, Walker TJ. Blood pressure in a Scottish Island Community. BMF 1969;iv:651-4.

26 Hawthorne VM, Gillis CR, Maclean DS. Monitoring health in Scotland. Int f Epidemiol 1972;1:369-74.

27 Hawthorne VM, Fry JS. Smoking and health: the association between smoking behaviour, total mortality, and cardiorespiratory disease in west central Scotland. f Epidemiol Community Health 1978;32:260-6.

28 Hawthorne VM, Watt GMC, Hart CL, Hole DJ, Davey Smith G, Gillis CR. Cardiorespiratory disease in men and women in urban Scotland: Baseline characteristics of the Renfrew/Paisley (Midspan) study population. Scott Med $\mathcal{F}$ 1995;40:102-7.

29 Rose GA, Blackburn H, Gillum RF, Prineas RJ. Cardiovascular survey methods. Geneva: WHO, 1982.

30 Medical Research Council. Definition and classification of chronic bronchitis for epidemiological purposes. Lancet 1965;i:775-9.

31 OPCS. Classification of Occupations 1966. London: HMSO, 1966.

32 Cox DR. Regression models and life tables. 7 R Stat Soc $B$ 1972;34:187-220.

33 Harding S. Social class differences in mortality of men: recent evidence from the OPCS Longitudinal Study. Population Trends 1995;80:31-7.

34 Office of Population Censuses and Surveys. Occupational mortality 1979-1980, 1982-1983. London: HMSO, 1986.

35 Osborne GS. Scottish and English schools. London: Longmans, 1966.

36 Hunter SL. The Scottish educational system. 2nd ed. Oxford: Pergamon Press, 1972.
37 Elo IT, Preston SH. Educational differentials in mortality: United States, 1979-85. Soc Sci Med 1996;42:47-57.

38 Menchik PL. Economic status as a determinant of mortality among black and white older men: does poverty kill? Population Studies 1993;47:427-36.

39 Bosma H. A cross-cultural comparison of the role of some psychosocial factors in the etiology of coronary heart disease. Den Haag: CIP-DATA Koninklijke Bibliotheek, 1994.

40 Seltzer CC, Jablon S. Army rank and subsequent mortality by cause: 23-year follow-up. Am f Epidemiol 1977;105:55966.

41 Holme I, Helgeland A, Hjermann I, Leren P, Lund-Larsen PG. Four-year mortality by some socio-economic indicators: the Oslo Study. 7 Epidemiol Community Health 1980;34:48-52.

42 Leigh JP. Direct and indirect effects of education on health. Soc Sci Med 1983;17:227-34.

43 Kenkel DS. Health behavior, health knowledge, and schooling. Fournal of Political Economy 1991;99:287-305.

44 Farrell P, Fuchs VR. Schooling and health: the cigarette connection. F Health Econ 1982;1:21 7-30.

45 Blane D, Hart C L, Davey Smith G, Gillis C R, Hole D J, Hawthorne V M. Association of cardiovascular disease risk factors with socioeconomic position during childhood and factors with socioeconomic position during
during adulthood. BM7 1996;313:1434-8.

46 Barker DJP. Mothers, babies and disease in later life. London: BMJ Publications, 1994

47 Davey Smith G, Hart C, Blane D, Gillis C, Hawthorne V. Lifetime socioeconomic position and mortality: prospective observational study. BMF 1997;314:547-52.

48 Davey Smith G, Ben-Shlomo Y. Geographical and social class differentials in stroke mortality - the influence of early-life factors. 7 Epidemiol Community Health 1997;51: $134-7$. 